\title{
Synectics in Teaching Grade 9 Science
}

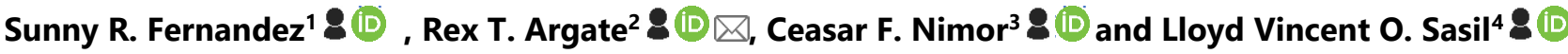 \\ ${ }^{1}$ Faculty, College of Teacher Education, Cebu Normal University - Main, Cebu City, Philippines \\ ${ }^{2}$ Faculty, College of Teacher Education, University of Cebu - Main, Cebu City, Philippines \\ ${ }^{3}$ Faculty, Graduate School, University of Cebu - Main, Cebu City, Philippines \\ ${ }^{4}$ Faculty, College of Arts and Sciences, University of Cebu - Main, Cebu City, Philippines
}

$\triangle$ Corresponding Author: Rex T. Argate, E-mail: rargate@uc.edu.ph

ARTICLE INFORMATION ABSTRACT

Received: May 08, 2021

Accepted: June 14, 2021

Volume: 3

Issue: 8

DOI: $10.32996 /$ jweep.2021.3.8.2

\section{KEYWORDS}

Synectics, teaching, quasi-

experimental, Cebu, Philippines
This study determined the effectiveness of synectics in teaching Grade 9 science in one private high school in Mandaue City, Cebu. A quasi-experimental design using the control and experimental groups was utilized. The experimental group was taught science concepts using synectics, while the lecture method was used in teaching the control group. Pretest and posttest evaluations were utilized to measure the academic performance of both groups of students. The results of the study showed that the pretest scores of the control and experimental groups on the three topics covered were fair and that the pretest mean values for the two groups were comparable or closer with each other. It also revealed that the posttest scores of both groups marked an increase in good performance level and the posttest mean value of the group with an intervention using synectics in teaching was greatly or highly improved compared to the group taught using the lecture method. The results also showed that there was a significant difference in the pretest and posttest scores between the control and experimental groups. Using synectics in teaching science concepts is an effective technique in improving students 'performance since it provides them with a meaningful and authentic understanding of scientific concepts by associating these concepts to real-life situations.

\section{Introduction}

In the Philippines, the students' current performance in science lags behind their international peers as a result of an international comparative survey test, which compared students' academic achievement across countries. In addition, according to the Department of Education in 2011, nearly two-thirds of the high schools in the country did below par in S.Y. 2009-2010 with $67.10 \%$ of the schools attaining scores below average. Thus, in science, it has been shown that students have not mastered the skills ranging from understanding or internalizing scientific data and information to explaining scientific theories or laws and being able to do the necessary calculations to solve scientific problems.

In one private high school in Mandaue City, Cebu, science teachers discussed that their students had difficulty coping with problem-solving in science during the subject area meeting. They observed that students had poor thinking and analytical skills which are very important factors in any problem-solving. They also observed that students should master first the concepts in science before dealing with the scientific problems. In addition, during the Professional Learning Community (PLC) meeting in the same school, different subject teachers gathered and discussed the same problem of students in subjects that involve computations and calculations. They found out that students should understand the concepts ahead so that they will be able to solve and calculate any scientific problems.

In grade 9, the science learning area focuses on the fundamental concepts and basic knowledge in Physics, Chemistry, Biology, Earth Science and Space Science. This includes the various competencies of the four areas of science wherein the same knowledge

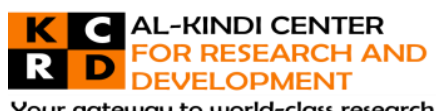

Your gateway to world-class research

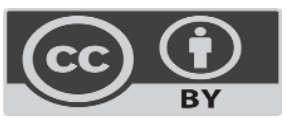

Published by Al-Kindi Center for Research and Development. Copyright (c) the author(s). This open access article is distributed under a Creative Commons Attribution (CC-BY) 4.0 license 
and concepts are taught with increasing difficulty and complexity across levels from grades three to ten. For instance, in the fourth grading period of the school year, the competencies for grade 9 science cover the topics on Physics such as free fall and projectile motion which need a thorough understanding of these concepts before dealing with problem-solving on these topics.

Moreover, the researcher experienced the difficulty of teaching grade 9 science, especially when the lesson involves problemsolving, which really needs the thinking and analytical skills of the students. The researcher observed that the students had difficulty in answering and solving word problems in a science subject. It was observed that the students easily understand the science concepts when they can associate and relate the concepts to objects in real-life situations. The students do not just associate and relate the concepts to any objects but also think about the why and how. With this experience, the researcher desired to use objects or analogies in teaching science concepts to know its effectiveness and usefulness in helping students understand the science concepts better. The researcher believes that the innovation of teaching strategies into more creative techniques would change students' performance in science.

\section{Review of Related Literature and Studies}

In order to succeed in the information age, the 21st-century skills are needed to develop a set of abilities in every students. These 21st Century Skills list three types: learning skills that include critical thinking, creative thinking, collaborating, and communicating. Literacy skills which include information, media, and technology literacy, and life skills which are flexibility, initiative, social skills, productivity, and leadership.

Synectics is the most highly refined and universally applicable of all the creative problem-solving techniques. Hummel (2006) defined synectics as a brainstorming technique used in problem-solving developed by William J. Gordon in 1961. Synectics is considered to be a complete problem-solving technique that is particularly useful for identifying problems and developing ideas. The main goal of this technique is to use two operational mechanisms to make the strange seem familiar and to make the familiar strange to produce the necessary psychological states needed to achieve creative responses. These psychological states are deferment of premature solutions, the autonomy of object and hedonic response, speculation, and involvement and detachment.

According to Salandanan (2009), the use of synectics in teaching enhances the student's creativity. The use of analogies is considered to be an important element of synectics. Generously using analogies helps in analyzing learning situations that call for new solutions, ideas and ways of doing things.

Bruce et al. (2000) say that the main element of synectics is the use of analogies. Thus, in this model, the students work with analogies and then they make metaphoric comparisons. The purpose of these analogies is that the students use it to solve a problem or to arrive at an idea. Of all the ideation techniques, synectics is considered by most experts to be the most difficult to perform. Before attempting to perform synectics, skills and experience need to be acquired (Stein, 1998). Since the origins of the technique are rooted in brainstorming, it aims to open up a problem to new insights. Synectics combines unrelated factors to allow one who is solving a problem to view that problem from varied perspectives.

As a problem-solving approach, synectics stimulates thought processes of which the subject is generally not aware. It is a method for inventing new solutions to problems. There is no attempt done to define the problem (Patil, 2012). The client's statement of the problem is taken as the starting point; he or she gives a brief explanation of the background as he or she sees it and then restates or paraphrases the problem in a language of 'how to' statements. These can be as speculative, unrealistic, and wishful or challenging as the group feels inclined to produce. Their purpose is to open up the whole problem area and give the client an opportunity to get away from conventional ways of looking at the problem.

A synectics technique is especially helpful in making scientific attitude, critical thinking and creative intelligence more understandable, meaningful, and effective (De Bono, 1990). Synectics techniques as a supplementary strategy were also found to be equally advance for students' because the use of synectics techniques increased interest and enhanced motivation levels. It also makes things simple and understandable, promotes creative thinking and enhances or utilizes the left and right sides of the human brain.

Many studies have been conducted worldwide to try out different methods in developing creativity through the synectics model of teaching. Some of the conducted researches are mentioned in the following:

Arkasali (2004), in his study on the effectiveness of the synectics model of teaching in terms of instructional and nurturant effects, found out the synectics model of teaching (strategy-I and Strategy-II) got nurturant instructional effects in general creativity in Kannada language and essay/paragraph writing in Kannada language. The results of the study also revealed that the use of synectics model of teaching is effective in Kannada language creativity writing in story construction, poetic diction, descriptive style and vocabulary test amongst the secondary school students. 
Tajri (2006) also found a difference between the academic performance of students who learn social education lessons with the use of the synectics method and those who learn it using the traditional lecture method. Synectics teaching method leads to increasing creativity in answers, ideas and activities of students. In other words, using the teaching method provides the groundwork for creative ideas (Ahmadi, 2011).

Ghamari (2011) has demonstrated in a study that using synectics teaching patterns (direct comparison) in educational lessons leads to improvement of students' performance in learning and remembering. The language creativity of students is enhanced when they are exposed to the synectics model of teaching (Shinde, 2011).

Synectics pattern leads to improvement in students' performance in both creativity and educational attainment (Abd Al-Maleki, 2011).

The educational attainment in social skills lessons of students who were taught using the synectics method was higher than those students who were taught using the traditional lecture method. Teaching life skills using the synectics method has also shown a positive impact on students' attitudes, skills, and knowledge (Ahmadi et al., 2013).

The studies mentioned above showed the effectiveness of synectics in language creativity and how its successful utilization brings more classroom activities to produce new ideas and new combinations. It also showed that the impact of using synectics teaching method is more positive than traditional methods do. Thus, the teaching method leads to the improvement of students' performance. Moreover, these studies also showed that the ability of students to solve problems is highly dependent on understanding the language used and on their creativity to associate ideas to real-life situations.

\section{Research Problem}

This study determined the effectiveness of the use of synectics in teaching Grade 9 science in one private high school in Mandaue City, Cebu. The result was used as the basis for a proposed action plan.

Specifically, the study sought answers to the following queries:

a. What are the pretest performances of the control and experimental groups?

b. What are the posttest performances of the control and experimental groups?

c. Is there a significant difference between the pretest performances of the control and experimental groups?

d. Is there a significant difference between the pretest and posttest performances of the control and experimental groups?

e. Is there a significant difference between the post-test performances of the control and experimental groups?

f. Based on the findings of the study, what action plan can be proposed?

\section{Methodology}

The study used the quasi-experimental method. It was conducted in one of the private high schools in Mandaue City, Cebu. Only 2 sections with 30 students each were selected as subjects in the study. The groups were formed by matching and pairing the subjects according to gender, age, and final grade in Science 8 . This study utilized a 50-item multiple-choice researcher-made instrument crafted according to the level of the students and was based on the competencies of the Department of Education. The 50-item researcher-made instrument, which was used for the pretest and posttest, was pilot tested and its reliability was tested and analyzed using Cronbach's Alpha. When the pilot-test data proved valid and reliable, the gathering of data of the subjects commenced until all data were retrieved, recorded, tabulated and analyzed. Statistical tools and formulas were used to measure, analyze and evaluate the performances of the subjects in terms of their scores from the pretest and posttest. Count of Frequency, Per Cent, Mean, Differences of Means, Lower Bound and Upper Bound Differences, Standard Deviation and Effect Size were statistical parameters and approaches used to evaluate, analyze, and interpret the scores of the two groups from the pretest and posttest performances. Scores were compared and analyzed to answer the main problem of this study: the pretest and posttest performances based on the scores of the control and experimental groups. The t-test for Independent Samples was utilized to determine the significance of the difference between the pretest scores or performances of the two groups; and posttest scores or performances of both groups. The paired t-test for Means was utilized to determine the significance of the difference between the pretest and posttest performances of the control and experimental groups.

\section{Results and Discussion}

Pretest Performances of the Control and Experimental Groups

Table 1 shows the pretest performances of the control and the experimental groups of the Grade 9 students on the fourth grading topics in science. 
Table 1: Pretest Performances of the Control and Experimental Groups

\begin{tabular}{|c|c|c|c|c|c|}
\hline \multirow{2}{*}{$\begin{array}{c}\text { Percentage } \\
\text { Score Ranges }\end{array}$} & Interpretation & $\begin{array}{c}\text { Frequency } \\
(\mathrm{f})\end{array}$ & Per Cent (\%) & $\begin{array}{c}\text { Frequency } \\
(\mathrm{f})\end{array}$ & Per Cent (\%) \\
\cline { 3 - 6 } & Very Good & 0 & 0.00 & 0 & 0.00 \\
\hline $76-100$ & Good & 12 & 40.00 & 13 & 43.33 \\
\hline $51-75$ & Fair & 17 & 56.67 & 17 & 56.67 \\
\hline $26-50$ & Poor & 1 & 3.33 & 0 & 0.00 \\
\hline $1-25$ & 30 & 100.00 & 30 & 100.00 \\
\hline \multicolumn{2}{|c|}{35.17} & & 36.83 \\
\hline
\end{tabular}

Table 1 shows the pretest performances of the control and experimental groups on the three topics in grade 9 namely: free fall, projectile thrown horizontally, and projectile thrown at an angle. Most of the students' pretest scores in the control group were fair, while only 1 or $3.33 \%$ got poor performance. Twelve or $40 \%$ got good performance. It showed that majority of the students need to learn more and understand better the three topics. As to the pretest scores of the experimental group, 17 out of 30 or $56.67 \%$ got fair performance, while 13 or $43.33 \%$ got good performance. It showed that most of the grade 9 students need mastery and understanding of the three topics. The control group has a mean score of 35.17 , while the other group has a mean of 36.83. The standard deviation of the two groups is 13.90 for the control group and 12.60 for the experimental group. It showed that students of the two groups had the same level of understanding with regard to the topic. It is further asserted that the students were having difficulty understanding and answering the test because of the limited background or prior knowledge about the topic. Table 2 also showed that students in both groups still need to learn and master the fourth grading topic in grade 9 science. This also showed that the students in the control and experimental groups are comparable.

\section{Posttest Performances of the Control and Experimental Groups}

Table 2 presents the posttest performances of the control and the experimental groups of the Grade 9 students on the fourth grading topics in science.

Table 2: Posttest Performances of the Control and Experimental Groups

\begin{tabular}{|c|c|c|c|c|c|}
\hline \multirow{2}{*}{$\begin{array}{c}\text { Percentage } \\
\text { Score } \\
\text { Ranges }\end{array}$} & \multirow[b]{2}{*}{ Interpretation } & \multicolumn{2}{|c|}{ Control Group } & \multicolumn{2}{|c|}{ Experimental Group } \\
\hline & & $\begin{array}{c}\text { Frequency } \\
\text { (f) }\end{array}$ & Per Cent (\%) & $\begin{array}{c}\text { Frequency } \\
\text { (f) }\end{array}$ & Per Cent (\%) \\
\hline $76-100$ & Very Good & 1 & 3.33 & 4 & 13.33 \\
\hline $51-75$ & Good & 22 & 73.33 & 25 & 83.33 \\
\hline $26-50$ & Fair & 7 & 23.33 & 1 & 3.33 \\
\hline $1-25$ & Poor & 0 & 0.00 & 0 & 0.00 \\
\hline \multicolumn{2}{|c|}{ Total } & 30 & 100.00 & 30 & 100.00 \\
\hline \multicolumn{2}{|c|}{ Mean } & \multicolumn{2}{|c|}{46.00} & \multicolumn{2}{|c|}{53.50} \\
\hline \multicolumn{2}{|c|}{ Standard Deviation } & \multicolumn{2}{|c|}{12.11} & \multicolumn{2}{|c|}{10.06} \\
\hline
\end{tabular}

Table 2 displays the subjects' posttest performances of the two groups. The students in the control group had a good performance, which is 22 out of 30 (73.33\%); while 7 or 23.33\% got fair performance. Only 1 or $3.33 \%$ got very good performance. There is an increase in the students' performance who are exposed to lecture method in presenting the topics. It means the lecture method is quite a good method in teaching science concepts. In the experimental group, 25 out of 30 or $83.33 \%$ got good performance, while only 1 or $3.33 \%$ got fair performance and 4 or $13.33 \%$ got very good performance. It showed that the use of synectics in teaching greatly improves the students' performance because the majority of the students in the experimental group got a good performance and a number of students got a very good performance. The experimental group has a slightly higher mean $(m=53.50)$ than the control group $(m=46.00)$. The standard deviation of the control and experimental group are 12.11 and 10.06, respectively. Table 3 further showed that there were gains of score and improvement of students' performance both in the control and experimental groups. It showed that the two methods of teaching helped improve students' performance on the three topics. However, it was evident that the use of synectics in teaching grade 9 science greatly 
affects students' learning. The results showed that students performed better in science when they were taught using synectics because they were actively involved in the teaching-learning process.

\section{Difference between the Pretest Performances of the Control and Experimental Groups}

Table 3 presents the significance of the difference between the pretest performances of the control and experimental groups of the Grade 9 students on the fourth grading topics.

Table 3: Significance of the Difference between the Pretest Performances of the Control and Experimental Groups

\begin{tabular}{|c|c|c|c|c|}
\hline Variable & $p$-Value & $\begin{array}{c}\text { Level of Significance } \\
(\alpha)\end{array}$ & $\begin{array}{c}\text { Decision on } \\
\text { Ho }\end{array}$ & Interpretation \\
\hline $\begin{array}{c}\text { Pretest Performances of the } \\
\begin{array}{c}\text { Control and } \\
\text { Experimental Groups }\end{array}\end{array}$ & 0.628 & 0.05 & $\begin{array}{c}\text { Failed to } \\
\text { Reject Ho }\end{array}$ & $\begin{array}{c}\text { No Significant } \\
\text { Difference }\end{array}$ \\
\hline
\end{tabular}

Table 3 shows the computed or calculated $p$-value is 0.628 which is greatly higher than the set level of significance at $\alpha=0.05$. Thus, the data failed to reject Ho; therefore, there is no significant difference between the pretest performances of the control and experimental groups. It showed that students in both groups were comparable based on their performance before introducing the topic. It further showed that the students' prior knowledge on the three topics could not greatly affect their performance but rather, it would be the teaching strategy used in teaching the two groups.

Difference between the Pretest and Posttest Performances of the Control and Experimental Groups

Table 4 presents the difference between the pretest and posttest performances of the control and experimental groups of the Grade 9 students on the fourth grading topics.

Table 4: Significance of the Difference between the Pretest and Posttest Performances of the Control Group and Experimental Group of the Grade 9 Science Students

\begin{tabular}{|c|c|c|c|c|}
\hline Variable & $p$-Value & $\begin{array}{c}\text { Level of Significance } \\
(\alpha)\end{array}$ & Decision on Ho & Interpretation \\
\hline $\begin{array}{c}\text { Pretest and Posttest } \\
\text { Performances of the Control } \\
\text { Group }\end{array}$ & 0.000 & 0.05 & Reject Ho & Significantly Different \\
\hline $\begin{array}{c}\text { Pretest and Posttest } \\
\text { Performances of the } \\
\text { Experimental Group }\end{array}$ & 0.000 & 0.05 & Reject Ho & Significantly Different \\
\hline
\end{tabular}

Table 4 shows the significant difference between the pretest and posttest performances of the control and experimental groups of the Grade 9 Science students. The pretest and posttest performances of the control group gain, since the $p$-value is 0.000 and is lower than the set level of significance at $\alpha=0.05$, then it rejects Ho and there is significant difference. And the pretest and posttest performances also gain, since the $p$-value is 0.000 and is lower than the set level of significance at $\alpha=0.05$, then it rejects $\mathrm{Ho}$ and there is a significant difference. The table further showed that the posttest performances of the control and experimental groups were improved compared to the pretest performances because of the use of two teaching strategies, the lecture method and the synectics. It showed that the two methods are both good at teaching science concepts.

\section{Difference between the Posttest Performances of the Control and Experimental Groups}

Table 5 presents the significance of the difference between the posttest performances of the control and experimental groups of the Grade 9 students on the fourth grading topics. 
Table 5: Significance of the Difference between the Posttest Performances of the Control and Experimental Groups of Grade 9 Science Students

\begin{tabular}{|c|c|c|c|c|}
\hline Variable & $p$-Value & $\begin{array}{c}\text { Level of Significance } \\
(\alpha)\end{array}$ & $\begin{array}{c}\text { Decision on } \\
\text { Ho }\end{array}$ & Interpretation \\
\hline $\begin{array}{c}\text { Posttest Performances of the } \\
\text { Control and } \\
\text { Experimental Groups }\end{array}$ & 0.012 & 0.05 & Reject Ho & Significantly Different \\
\hline
\end{tabular}

Table 5 shows the significant difference in the posttest performances of the two groups. The computed or calculated $\mathrm{p}$-value is 0.012 and is lower than the set level of significance at $\alpha=0.05$; therefore, it rejects the null hypothesis. So, there is a significant difference between the posttest performances of the control and experimental groups. This implies that the use of synectics in teaching gave meaningful gain in the students' scores. Table 6 further showed that the posttest performances of the experimental group were greatly improved compared to the posttest performances of the control group. It revealed that the use of synectics in teaching greatly affects the students' performance compared to the performance of the students who were taught using the lecture method.

\section{Conclusion and Recommendation}

The use of synectics in teaching grade 9 science has been proven to be an effective technique to improve the performance of students and their learning on conceptual knowledge. Students who were taught using this technique have a marked improvement in their test scores. As a teaching technique, synectics provides students with a meaningful and authentic understanding of scientific concepts by associating these concepts to real-life situations. Furthermore, it is recommended to use synectics in teaching science concepts in other areas such as biology, chemistry, and earth science. The science topics should be carefully selected to which they can be best delivered and taught using synectics.

\section{References}

[1] Abd Al-Maleki, Sh. (2011). Studying the impact of synectics teaching method on creativity and educational attainment of the life skills lesson in junior high school students in Sanandaj City. [M.A. thesis] Shahid Rajae University.

[2] Ahmadi, B. (2011). Modernity and Critical Thought. Tehran: Doran.

[3] Ahmadi, Gh., Osareh, A., and Abdolmaleki, Sh.(2013). The effect of synectics teaching method on knowledge, skills, attitudes of first year high school students in life skills lesson. Journal of educational innovations, 11 (4), 63-81.

[4] Arkasali, R.N. (2004). Effectiveness of the synectics model of teaching in terms of instructional and nurturerant effects. Karnatak University, Dharwad. Unpublished doctoral dissertation.

[5] Bruce, J. et al. (2000). Models of Teaching. United States of America: Allyn and Bacon.

[6] De Bono, E. (1990). Lateral Thinking: A Textbook of Creativity. Penguin Books Ltd. London: England.

[7] Ghamari, H. (2011). Study of the effect of using synectics teaching pattern (Direct Comparison) in educational attainment of third year high school students in "direct-current electrical machines" lesson. Unpublished M.A. thesis in educational science. Shahid Rajai University.

[8] Hummel, L. (2006). Synectics for creative thinking in technology Education. Retrieved on January 15, 2011 from ProQuest Education Journals.

[9] Kalyuga, S., Ayres, P., Chandler, P. \& Sweller, J. (2003). The expertise reversal effect. Educational Psychologist, 38 (1) 23-31.

[10] Oregon Technology in Education Council (OTEC) (2007). Situated learning (From: Theories and Transfer of Learning). http://otec.uoregon.edu/learning_theory.htm\#SituatedLearning.

[11] Patil, R. (2012). Effectiveness of synectics model (SM). Indian Streams Research Journal.

[12] Salandanan, G. (2009). Methods of Teaching. Manila:Lorimar Publishing, Inc.

[13] Shinde, S.N. (2011), Effect of the synectics model of teaching on the development of language creativity in Hindi amongst the students of Hindi B.Ed. colleges. Karnatak University, Dharwad. Unpublished doctoral dissertation.

[14] Stein, D. (1998). Situated learning in adult education. http://www.ericdigests.org/1998-3/adult-education.html

[15] Tajri, T. (2006). Studying and comparing synectics teaching methods and lecture method in fostering creativity and educational attainment in social education lesson. Unpublished Master of Arts thesis in educational sciences, Allameh Tabatabai University, Tehran. 